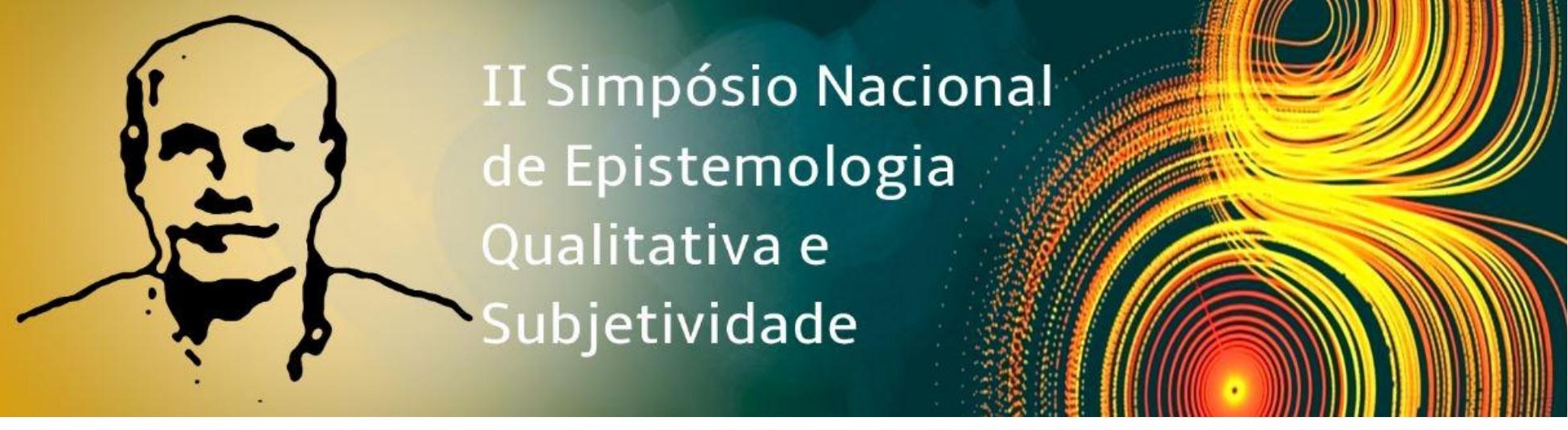

Eixo temático: Aprendizagem e dificuldades de aprendizagem na perspectiva da subjetividade

\title{
Ser sujeito no processo de aprender química
}

Priscilany Cavalcante dos Santos, Universidade Federal do Pará, priscilanysantos@yahoo.com.br Andrela Garibaldi Loureiro Parente, Universidade Federal do Pará, andrelagaribaldi40@gmail.com

\section{Resumo}

Aprender química envolve ser alfabetizado cientificamente (CACHAPUZ; PRAIA; JORGE, 2000). Porém, existem dificuldades de aprendizagens em química que contribuem para o desinteresse dos estudantes em aprender esta ciência (JOHNSTONE, 2000). Tais dificuldades são relacionadas à natureza desse conhecimento sendo de ordem epistemológica, ontológica e conceitual (POZO; CRESPO, 2009), à linguagem química (ROQUE; SILVA, 2008), e à inexistência de relações entre as dimensões do conhecimento químico (macro, micro e representacional) (JOHNSTONE, 2000). A partir da Teoria da Subjetividade temos defendido que as dificuldades não são somente em termos da natureza dos conteúdos e da linguagem, mas de ordem simbólica-emocional (GONZÁLEZ REY, 2005) no qual a dimensão relacional assume a centralidade da aprendizagem (TACCA, 2006), permitindo que a troca e negociação de significados estejam presentes entre os envolvidos no processo implicando em suas subjetividades. Os estudos de Rossato e Mitjáns Martínez (2011), Mitjáns Martínez e González Rey (2017) compreendem que as dificuldades de aprendizagens vão além do aspecto cognitivo, pois envolve processos complexos, sistêmicos e recursivos. Assim, considerar como central a dimensão subjetiva da aprendizagem ajuda a compreender o processo de aprender química sob outra ótica. Nessa perspectiva, a imaginação torna-se essencial para valorizar o sujeito da aprendizagem, já que "indica o caráter subjetivo de uma produção humana" (GONZÁLEZ REY, 2014, p.44). Este estudo, ainda em desenvolvimento, objetiva investigar as dificuldades de aprendizagens numa dimensão subjetiva do aprender química, assumindo os princípios da Epistemologia Qualitativa de González Rey (2005). Ao 


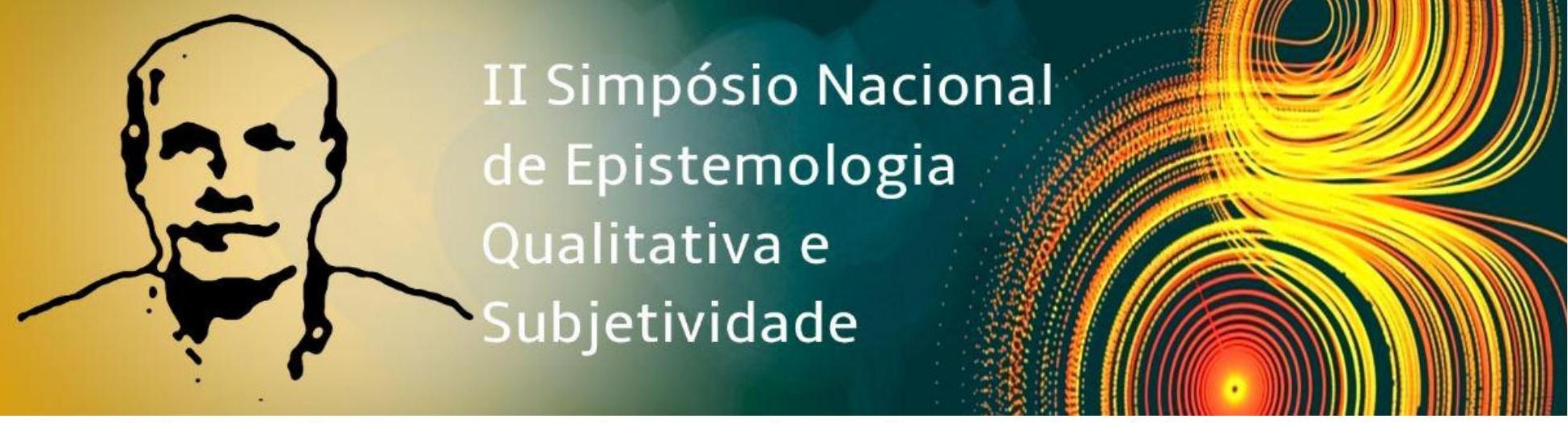

valorizar o estudante como o centro do processo de aprendizagem será possível alcançar uma alfabetização científica. Por isso, queremos saber: Em que termos a compreensão das dificuldades de aprendizagens em química pode contribuir com a alfabetização científica de estudantes da educação básica?

Palavras chave: aprendizagem, imaginação, química.

\section{Referências}

CACHAPUZ, A.; PRAIA, J.; JORGE, M. Perspectivas de ensino. In: Formação de Professores/Ciências, Nº1. CACHAPUZ, A (Org.). Centro de Estudos em Educação em Ciência: Porto, 2000.

GONZÁLEZ REY, F. L. Pesquisa qualitativa e subjetividade: os processos de construção da informação. São Paulo: Thomson, 2005.

JOHNSTONE, A. H. Teaching of chemistry - logical or psychological? Chemistry Education: Research and practice in Europe. v. 1, n. 1, 2000. p. 9-15.

MITJÁNS MARTÍNEZ, A.; GONZÁLEZ REY, F. L. Psicologia, educação e aprendizagem escolar: avançando na contribuição da leitura cultural-histórica. São Paulo: Cortez, 2017.

POZO, J. I.; CRESPO, M. A. G. Aprendizagem e o ensino de Ciências: do conhecimento cotidiano ao conhecimento científico. 5. ed. Porto alegre: Artmed, 2009. 296p.

ROQUE N. F.; SILVA J. L. P. B.; A linguagem química e o ensino da química orgânica. Quim. Nova, Vol. 31, N. 4, 2008. p.921-923.

ROSSATO, M.; MITJÁNS MARTÍNEZ, A. A superação das dificuldades de aprendizagem e as mudanças na subjetividade. In: Martínez, A. M;Tacca, M. C. V. R . (Org.). Possibilidades de aprendizagem - Ações pedagógicas para alunos com dificuldades e deficiência. 1ed. Campinas: Alínea, 2011, v. 1, p.71-107.

TACCA, M. C. V. R. Estratégias pedagógicas: conceituação e desdobramentos com o foco nas relações professor-aluno. Em: TACCA, M.C.V.R. Aprendizagem e trabalho pedagógico. Campinas: alínea, 2006. p. 45-68. 